Proceedings of the 50th Hawaii International Conference on System Sciences | 2017

\title{
Sorting out EHR adoption and assimilation in the Meaningful Use incentive program in Hawaii
}

\author{
Kelly Holden \\ University of Hawai'i at Manoa \\ kholden@hawaii.edu
}

\author{
Elizabeth Davidson \\ University of Hawai'i at Manoa \\ edavidso@hawaii.edu
}

\begin{abstract}
Both widespread adoption and meaningful assimilation are needed to achieve the full benefits of EHRs. In the U.S. the HITECH Act and its Meaningful Use (MU) program have stimulated EHR adoption to historically high levels. Questions remain about program efficacy and possible unintended consequences. In this paper, we report our analysis of Meaningful Use attestation data for the period 20112014 in the State of Hawai'i. Findings indicate that the MU program primarily stimulated deeper assimilation of EHRs among existing adopters in 2011, mostly in large practice groups. In subsequent years, EHR adoption and assimilation, evidenced by $M U$ attestation, increased then peaked among small, independent practices. In the final study year, attestation rates dropped for small practices, although only one third of eligible providers have attested, while attestation among larger practices remained steady as this group shifted to the next MU stage. Findings suggest small practices, particularly primary care and rural practices, continue to face high barriers to meaningful EHR adoption and assimilation. Findings suggest better targeted policies and incentives may be needed to keep this promising program on track.
\end{abstract}

\section{Introduction}

In the United States and elsewhere, the use of health information technology to promote health system improvements has become a topic of much interest and concern. Policymakers have developed programs aimed at the health care sector to promote HIT adoption, particularly the use of electronic health records (EHRs). In the U.S., adoption of EHRs was too low according to health information technologies (HIT) researchers, advocates and professionals [2], [16], [31], [32]. In 2010, Dr. David Blumenthal, the head of the Office of the National Coordinator for Health IT (ONC) commented that despite years of professional and bipartisan consensus about the benefits of EMR benefits, this innovation was still largely restricted to large healthcare organizations; few small practices or clinics where most Americans receive their primary health care had access to these systems [35]. This disconnect was attributed to "cultural barriers and chronic market failures" [35]. Although many barriers to widespread adoption of EHRs were identified, financial barriers, notably the high cost to buy and implement an EHR and the lack of incentives for health care providers to make this investment, could be addressed via federal government policy and funding [3]. Lack of qualified health IT support services to help physicians implement EHRs was also identified as a target for U.S. federal policies and funding [4].

Because the U.S. federal government is the largest single payer in the healthcare system, and because widespread EHR use was viewed as a crucial tool to improve individual and population health management, transparency and efficiency of care and the ability to study care delivery systems, the U.S. government undertook a large-scale program to stimulate EHR adoption and use [4]. As part of the The American Recovery and Reinvestment Act of 2009, the Heath Information Technology for Economic and Clinical Health Act (HITECH) established programs under the Centers for Medicare and Medicaid (CMS) to stimulate widespread adoption and use of EHRs. In particular, the "Meaningful Use" program (MU) provided incentive payments for doctors who adopted a certified EHR technology and used it in ways specified by this program [14]. The MU program made available up to $\$ 27$ billion dollars nationwide to clinicians over a tenyear period through incentive payments. Each clinician could earn as much as $\$ 44,000$ by applying through the federal Medicare program, or $\$ 63,750$ by applying through state-run Medicaid programs [5]. The program was aimed not only to stimulate purchase of an EHR, but to require physicians use the program in increasingly robust ways: Stage 1 was to stimulate initial digitization of health records; Stage 2 builds on digitization to include quality measurement, clinical decision support, and information exchange; and Stage 
3 is aimed at improving health outcomes for both patients and populations [14].

The MU program of HITECH can be understood as promoting related facets of innovation diffusion: technology adoption and assimilation [18, 19]. First, MU incentives require physicians to adopt EHRs by purchasing (or otherwise acquiring) a system. Second, the MU program specifies specific (and increasing) ways a physician must use the EHR to qualify for incentives, requiring the physician to assimilate use into his or her daily practices. Widespread adoption across practices and meaningful assimilation within practices together supports the goals of building a pervasive health IT infrastructure in the U.S. healthcare system [3] [14] [19]. To qualify for incentive payments, physicians are required to "attest" that they are using a certified EHR and are meeting the MU criteria for use through an Internet interface with CMS. For instance, Stage 1 criteria include using electronic prescribing, maintaining problem lists for patients, and using certain clinical decision support tools in a certified EHR system. Thus "MU attestation" numbers provide an indicator of the extent of adoption and assimilation of EHRs into U.S. physician practices.

Six years since its initiation, many questions remain about the effectiveness of the MU program for achieving stated goals. As part of its open governance policy, the ONC publishes detailed reports on the status of the program to address some questions. Importantly, the ONC also publishes detailed data on physician attestation by state [6]. These data sets allow researchers and policy analysts to delve more deeply into program results to fully investigate theoretical and policy issues. In this paper, we report the results of such an investigation into the MU program for clinicians in the State of Hawai'i during the years 2011-2014. We chose the State of Hawai'i because of our in-depth knowledge of this healthcare market, which allowed us to enhance the value of ONCsupplied data with additional data (such as physician practice type, urban vs. rural practice) and to interpret aggregate numbers in light of state-level market characteristics. Complete ONC data was available for 2011-2014 at the time of our study.

In the following sections we briefly review the literature on the MU program as well as theoretical insights about organizational IT adoption such as EHRs. We then outline our research methods and present findings on EHR attestation in Hawai'i. Our analysis highlights progress with EHR adoption and assimilation as well issues and concerns about future trends. The data are specific to the State of Hawai'i, but our literature review suggests these issues are representative of broad policy concerns.

\section{The Meaningful Use Program to-date}

The MU program represents a multi-level effort lead by CMS to stimulate adoption of EHRs to direct use in medical practice towards clinically useful practices that would improve outcomes. MU also aims to build the national HIT infrastructure that would allow health data sharing across clinicians. Therefore, there are several components to achieving MU: (i) increased adoption, (ii) assimilation into practice in clinically relevant ways (not just practice management), and (iii) national-level and communitylevel assimilation that builds the HIT infrastructure. In order to achieve this, MU incentive payments are specifically tied both to initial adoption and assimilation of EHRs by physicians in private practices and in hospital settings [5,22]. Widespread use is important to improve quality, safety and efficiency within practices and across healthcare settings [9].

Since its inception in 2009, and initiation of incentive payments in 2011, the ONC monitors progress through $\mathrm{MU}$ attestation by physicians for a given stage of the program $(1,2$ or 3$)$, as well as by surveys conducted among physicians and commissioned evaluation reports. Official, aggregate statistics suggest the program has been successful on several important fronts. For instance, in 2015 the ONC reported that $95 \%$ of all eligible and critical access hospitals had demonstrated meaningful use of certified health IT systems, with some states with large rural areas (e.g., Alaska, Hawai'i, Texas) lagging slightly. ${ }^{1}$ In contrast, $56 \%$ of office-based physicians had demonstrated meaningful use, with only a few states having higher rates. ${ }^{2}$ This last statistic is important, as much healthcare in the US is delivered by office-based physicians in small practices. (Our study focuses on these practices, as we discuss shortly.)

As the meaningful use program continues, the challenge for policymakers and physicians alike will be to ensure that MU actually results in meaningful benefits and outcomes [9]. Studies of the MU program thus far suggest a more difficult task than aggregate attestation numbers alone would indicate. Early reports are beginning to appear in the literature, e.g., [13] [21] [22] [26] [29] [33] [37] [38] [39]. Here, we highlight key findings and observations.

First, professional groups, such as the American Medical Association (AMA) have critiqued the content and schedule of the MU program, as have EHR

\footnotetext{
${ }^{1}$ http://dashboard.healthit.gov/quickstats/pages/FIGHospitals-EHR-Incentive-Programs.php

2 http://dashboard.healthit.gov/quickstats/pages/FIG-HealthCare-Professionals-EHR-Incentive-Programs.php
} 
technology vendors who must enhance their software and undergo certification to meet the MU criteria. As a result, the timeline for MU stages has been extended and certain criteria have been dropped or modified (such as ensuring electronic data exchange with patients.). Delays are due in part to the initial highly aggressive timeline set forth by policymakers to implement MU within the 10-year timeframe and issues in the technology market with vendors. Organizations such as the AMA have criticized requirements that they suggest could "lead to the commodification of heretofore 'professional' skills as industrial models increase pressure to broaden the scope of practice for non- or paraprofessionals" [35]. The latest delay, announced June 2016, "intends to extend the timeline for Stage 2 and delay Stage 3 meaningful use attestation. The new timeline would extend Stage 2 meaningful use through 2016. Stage 3 would begin in 2017 for providers who have completed at least two years in Stage 2." [15]. Despite the progress suggested by ONC attestation numbers, these delays indicate significant implementation issues.

Resistance is due in part to what some researchers label misaligned incentives in the health care markets between "those who pay (insurers), those who recommend treatment (providers), and those who experience treatment (patients)." [35]. While insurers and patients may see value in a physician using an EHR, providers may find that incentive payments do not compensate them adequately for the additional time spent documenting their work and ongoing costs of the EHR [13]. "If nothing else, this explains why vertically integrated providers (merging as they do the insurance and care functions) appear disproportionately on lists of those who have successfully implemented comprehensive EMRs." [35].

An ancillary impact that researchers have identified is stifled innovation. The Office of the National Coordinator for Health Information Technology (ONC) aims to encourage innovation and create "an environment of testing, learning, and improving, thereby fostering breakthroughs that quickly and radically transform health care" [39]. Policymakers may have underestimated the impact meeting MU program requirements would have on organizations. Although HITECH provides some incentives and implementation support resources, many organizations face the ongoing issue of diverting time and attention to simply meeting basic MU requirements, diverting attention from finding solutions to other local and national health care reform priorities [23] [33].

The national level MU program is intended to promote both widespread adoption of EHRs across the various healthcare settings (ambulatory and in-hospital, small and large groups, rural and urban, etc.) and to ensure assimilation of a minimal set of EHR use practices (the MU criteria) [3], [4], [5]. However, healthcare settings vary greatly in organizational characteristics and thus in their ability to assimilate complex organizational technologies such as EHRs (e.g. [37], [38]). Studies have shown that there are disparities in adoption of EHRs among ambulatory care providers due to multiple factors that are not addressed by the current MU policies and incentives. A 2016 meta-analysis of MU studies [37] identified the following factors influencing rates of adoption and attestation: urban versus rural location, practice size, and patient population factors such as payer mix and race/ ethnicity. One conclusion rom the meta-analysis is that a "one size fits all" EHR incentive program cannot address the complexities and disparities across the U.S. healthcare system. [37] This conclusion is shared by other researchers (e.g. [5], [38]) in this area who agree that MU and HITECH "must be calibrated to reflect both the capacities of the providers who face a multitude of real-world challenges and the maturity of the technology itself." [5]

\section{EHR adoption and assimilation theory}

IT assimilation research suggests such findings are not surprising. Research has shown that adoption of any IT innovation is impacted by an organization's ability to acquire and implement the innovation into the organization [18], [19]. Moreover, barriers differ for different sizes and types of organizations. For instance, larger organizations are generally more robust adopters of innovations, as they have the capacity to learn about and integrate new technologies. Plus, they have a greater potential to benefit from the innovation across the enterprise [18]. This is evident in healthcare settings as well, as large organizations such as hospitals have resources to dedicate to IT innovation projects, whereas small healthcare organizations do not [10]. Of note, prior to the MU program, many surveys and research reports illustrated that practice size was consistently associated with EHR adoption, in that small practices were consistently the least likely to have adopted an EHR system [31] [32].

In healthcare settings practice size, and secondarily practice location, are generally associated with organizational resources needed to assimilate IT innovations. (Rural healthcare settings tend to be small, understaffed, and remote from market resources such as consultants.) In general, small practice physicians are independent providers who may work with 1-5 physician partners in a practice they own, and support staff (nurses, lab techs, administrative staff) is usually minimal. Large physician practices are traditionally 
associated with larger health systems and are aligned with hospitals and medical centers. These practices typically have highly integrated information systems, and support staff for administrative, diagnostic and clerical needs.

Though EHR adoption and assimilation is costly for all organizations, larger organizations have greater staff resources [11] than small practices to do so. In fact, the physicians/owners may be the only resources who can decide what software package to purchase, manage the implementation project, and design the workflow changes for his or her office [12]. Front-line providers (physicians, nurses, specialists, lab, imaging and other technical staff), clerical staff and operations staff must understand the EHR and utilize it appropriately [17]. Challenges to doing so include lack of EHR knowledge, workflow disruptions, and lack of interoperability" [39], requiring resources, such as IT specialists, workflow analysts, and trainers [10]. Having long lagged in EHR adoption, small independent (community) practices may continue to lag with meaningful use attestation as they struggle with assimilation, or they may choose not to adopt and accept financial payment penalties from Medicare for failure to comply $[5,13,20]$.

\section{Research study design and methods}

Given the importance of small physician practices to the overall U.S. healthcare system, previous research that indicates these types of organizations are most likely to be challenged by EHR adoption and the requirements of the MU program, and conflicting indications of the impacts of the MU program beyond the aggregate numbers reported by the program's sponsor (CMS/ONC), our study was designed to look in depth at one healthcare organizational field: physician practices in the State of Hawai'i. We chose Hawai'i because the authors had access to information on the progress of the MU program during the years studied (2011-2014) through their work and research (e.g., [12], [13]) and could add detailed data to the datasets provided by $\mathrm{ONC}$, in order to deepen analysis of the MU program outcomes. Although unique in some ways, Hawai'i has a mix of small and large practice groups as well as a mix of urban vs. rural practices that would be found in most states in the U.S.

In the study reported here, we used data from the public records that CMS [6] makes available. In spring, 2016, data on the years 2011-2014 were fully available for Medicare MU incentive recipients. This data includes the physician's name, unique provider ID number, primary practice address, MU stage attested to (Stage 1 or 2), and the dollar amount of incentive received. We cross-referenced this data with public information available through hospital and clinic websites and databases to add the clinician's primary specialty, and secondary specialty. For analysis we coded for primary care provider (internal medicine, family practice, $\mathrm{OB} / \mathrm{GYN}$, pediatrician) or specialist (any subspecialty outside of primary care); rural (the counties of Maui, Hawaii and Kauai as well as the North Shore and Leeward coast of Honolulu County) or urban (urban Honolulu County, except for stated areas identified as rural) practice location; and whether or not the clinician was employed by a large health system or was an independent or small group practice provider (Practice of less than 5 providers).

We further analyzed the data by identifying unique instances of a physician attesting to meaningful use, in order to determine which year MU attestation first occurred. For instance, if Dr. X attested in 2011 and 2012, we counted Dr. X as a unique attester in 2011. We looked at ongoing participation in the program, in total attestations per year and continuity of attestation by individual physicians across the four years.

The ONC data sets provide a complete census of physicians attesting to via the Medicare program in the State of Hawai'i but it does not give a census of potential attesting physicians. Developing a list of "physicians practicing in Hawai' $i$ " is a complicated task, as some physicians licensed in Hawai'i have retired or moved away, and some no longer practice. Thus we relied on the 2015 Annual Report to the Legislature [36] created by the University of Hawaii. This report identifies 3,596 actively practicing physicians who are not military doctors (who are not part of the MU program). The report equates this number to 2,806 full-time equivalents for workforce planning purposes, but since a physician can attest to MU without being a full-time provider, we used 3,596 as the best estimate of all eligible MU physicians in Hawai'i. The Annual Report estimates that 711 physicians are over the age of 65 in 2015 (20\%), 31\% are female with $69 \%$ male and $58 \%$ work in practices smaller than five providers (considered independent and small practice physicians in this study) [36]. Of note, the $58 \%$ in small practices is consistent with earlier national reports of the percentage of small practices in the U.S. [32].

With these enhanced data, we preformed descriptive statistical analysis along key organizational dimensions that empirical and theoretical studies indicate are important for EHR adoption and assimilation and own interests in independent practice physicians: MU attestation among employed versus independent practices, specialty care versus primary care, and geographic practice area differences (urban versus rural). This study assessed attestation data for evidence on adoption and assimilation by practice size, 
specialty and practice location. Attestation to stage 1 indicates initial adoption and assimilation. Stage 2 attestation indicates enhanced assimilation. We also assessed the rate of MU attestation within the organizational field overall.

\section{Findings}

We next consider progress as well as areas of concern with the MU program and the implications for EHR adoption and assimilation attestation rates indicate.

\subsection{Time to adoption vs assimilation}

Table 1 indicates that, in the first 4 years of the MU program incentive payments, 1,034 Hawai'i physicians attested to Stage 1 of the MU program. Of these, $21 \%$ of new attestation occurred in Year 1. In year 1, 61\% of those attesting were physicians employed by a large physician organization, which had installed an industry standard EHR several years earlier. We identified some of the independent physicians attesting that year as previous EHR adopters as well [13]. Thus we concluded that the MU program initially stimulated deeper assimilation among existing EHR adopters.

In Year 2, 46\% of first-time attestation occurred, with $88 \%$ of first-time attesters in independent practices. We identified some independent physicians as early EHR adopters (pre-MU program) as were all the Year 2 employed physicians). However this shift suggests by Year 2 the MU program was stimulating new EHR adoption among small practices, rather than motivating only the early EHR users to attest to MU.

Overall, 68\% of first time attestation occurred in years 1 or 2 , indicating a sharp drop off in attestation rates in years 3 or 4 . We considered whether this meant that the MU program has saturated the Hawai' $i$ physician market. Using the estimate of 3,596 practicing physicians, total unique attestation from $2011-2014$ is $29 \%$ overall, and is about $35 \%$ of the independent physicians $(2085$, or $58 \%$ of 3,596$)$ [36]. These estimates are in alignment with the ONC estimate of $34 \%$ of Hawai'i physicians attesting to MU through Medicare, by December, $2015 .^{3}$

To summarize, the data suggests that some employed physicians assimilated the first stage of MU use practices quickly, since they had an EHR in place, but that further, new participation declined in the following years, with a 4-year attestation rate by employed physicians of about $20 \%$. This is odd, because employed physicians practicing in urban areas

\footnotetext{
${ }^{3}$ http://dashboard.healthit.gov/dashboards/physiciansmedicare-meaningful-use.php
}

all work for hospitals that had an advanced EHR in place prior to 2011. An explanation is that one integrated healthcare system may have delayed attestation until 2014, when the State of Hawai'i implemented the Medicaid MU program. We did not find any of these employed physicians in the ONC data set. While independent physicians using an EHR prior to 2011 were among the first to attest, the expected surge of adoption and assimilation is evident in year 2 and tapers off in years 3 and 4 . Since $65 \%$ of physicians in independent practices have not yet attested, we conclude that market saturation does not explain this fall-off, and that resistance to EHRs or difficulty meeting MU program goals are likely causes.

\section{Table 1. Unique attesters per year and by practice setting}

\begin{tabular}{|l|r|r|r|r|r|}
\hline $\begin{array}{l}\text { Attested } \\
\text { practice year }\end{array}$ & $\mathbf{2 0 1 1}$ & $\mathbf{2 0 1 2}$ & $\mathbf{2 0 1 3}$ & $\mathbf{2 0 1 4}$ & Total \\
\hline $\begin{array}{l}\text { Employed } \\
\text { Physicians }\end{array}$ & 137 & 59 & 49 & 55 & 300 \\
\hline $\begin{array}{l}\text { Independent/ } \\
\text { small practice }\end{array}$ & & & & & \\
Physicians & 87 & 416 & 165 & 66 & 734 \\
\hline Total & $\mathbf{2 2 4}$ & $\mathbf{4 7 5}$ & $\mathbf{2 1 4}$ & $\mathbf{1 2 1}$ & $\mathbf{1 0 3 4}$ \\
\hline
\end{tabular}

Table 2 reports all attestations that occurred in 2011-2014, including repeat attestation for Stage 1 and new Stage 2 attestation. Of note, attesting to Stage 1 for a second year required reporting on a full year's activity versus a 90-day period, indicating a somewhat higher level of assimilation that year of MU practices.

Attestation for both employed and independent physicians occurred in years 2011-2013 with increasing numbers, indicating that physicians were remaining active in the MU program by attesting in multiple years. However, in year 4 (2014), attestation rates decreased for independent physicians while they held steady for employed physicians. Attestation to Stage 2 first occurred in 2014, accounting for $9 \%$ of all attestations made. Of note, $68 \%$ of Stage 2 attestations were made by employed physicians, accounting for $18 \%$ of their attestations overall, whereas Stage 2 attestations by independent practices accounted for only $4 \%$ of their attestations.

Employed physicians demonstrated a continued increase in attestation over the four-year period, and only experienced an $18 \%$ drop-out rate for attesters (assessed as a physician failing to attest in a subsequent year). Independent physicians demonstrated a $41 \%$ drop-out rate for unique attesters over the four-year period, with the majority falling off in 2014 . We also noted the pattern we observed for new attesters (Table 
1), in which employed physicians dominated in the earliest phases, and independent physicians later dominated, may be reoccurring with Stage 2 assimilation. This suggests that for independent and small practice physicians, the ability to meet MU stage 2 criteria is more challenging than for employed physicians, but this group may later "catch up."

Table 2. Practice setting for attestation

\begin{tabular}{|c|c|c|c|c|c|}
\hline $\begin{array}{l}\text { Attested } \\
\text { practice } \\
\text { year }\end{array}$ & 2011 & 2012 & 2013 & 2014 & Total \\
\hline $\begin{array}{l}\text { Employed } \\
\text { Physicians - } \\
\text { stage } 1\end{array}$ & 137 & 191 & 222 & 100 & 650 \\
\hline $\begin{array}{l}\text { Employed } \\
\text { Physicians - } \\
\text { stage } 2\end{array}$ & -- & -- & -- & 146 & 146 \\
\hline $\begin{array}{l}\text { Employed } \\
\text { Physicians } \\
\text { - total }\end{array}$ & 137 & 191 & 222 & 246 & 796 \\
\hline $\begin{array}{l}\text { Independent/ } \\
\text { small } \\
\text { practice } \\
\text { Physicians - } \\
\text { stage } 1\end{array}$ & 87 & 485 & 579 & 362 & 1513 \\
\hline $\begin{array}{l}\text { Independent/ } \\
\text { small } \\
\text { practice } \\
\text { Physicians - } \\
\text { stage } 2\end{array}$ & -- & -- & -- & 69 & 69 \\
\hline $\begin{array}{l}\text { Independent } \\
\text { small } \\
\text { practice } \\
\text { Physicians - } \\
\text { stage total }\end{array}$ & 87 & 485 & 579 & 431 & 1582 \\
\hline Total & 224 & 676 & 801 & 677 & 2378 \\
\hline
\end{tabular}

To summarize, attestation rates in the MU program, an indication of increasing adoption and assimilation of EHRs among Hawai'i physicians, slowed in 2014 as MU criteria became more strenuous. While all physicians seem to be challenged by this level of assimilation ( $9 \%$ of attestations), physicians in independent practices seem most challenged. This suggests all physicians were more successful with MU stage 1 criteria than stage 2 , and employed physicians are more continuously successful meeting $\mathrm{MU}$ program criteria than physicians in small practices.

\subsection{Practice type and location effects}

Many researchers initially proposed that the MU program would more greatly impact primary care providers (PCPs), as managed care and meaningful use-type criteria for practices are often more closely associated with these providers. Our analysis of Hawai'i attestation data did not support this prediction.

As is seen in table 3, during the initial attestation year (2011), more PCPs in both employed and independent physicians' groups attested, however, the differences were not great (122 PCPs to 102 specialists). This trend continued as the number of attestations (new and renewing) increased, until 2013, when there was a shift toward more specialists attesting than PCPs. This suggests that PCPs may have been more likely to have an EHR prior to the first year of MU program incentives, and thus were quicker to attest, whereas specialists were delayed finding the right EHR for their practice needs. There is insufficient data to assess yet whether specialists will have a harder or easier time assimilating at the MU 2 level, as the vast majority attested at MU Stage 1 though 2014.

We also considered how practice location, in a rural or urban area, might influence MU program participation. (See Table 4.) Rural and urban populations vary in needs for primary and specialty care. In rural areas, access to physicians is perhaps more critical, as population health management in rural areas often involved much higher at risk populations due to lower socio-economic factors.

Table 3. PCP vs. specialty physician

\begin{tabular}{|l|r|r|r|r|r|r|r|r|}
\hline Attested practice year & \multicolumn{2}{|c|}{2011} & \multicolumn{2}{|c|}{2012} & \multicolumn{2}{|c|}{2013} & \multicolumn{2}{|c|}{2014} \\
\hline Specialty vs. PCP & PCP & specialty & PCP & specialty & PCP & specialty & PCP & specialty \\
\hline Employed Physicians & 71 & 66 & 96 & 95 & 109 & 113 & 111 & 135 \\
\hline $\begin{array}{l}\text { Independent/small } \\
\text { practice Physicians }\end{array}$ & 51 & 36 & 264 & 221 & 281 & 298 & 203 & 228 \\
\hline Grand Total & $\mathbf{1 2 2}$ & $\mathbf{1 0 2}$ & $\mathbf{3 6 0}$ & $\mathbf{3 1 6}$ & $\mathbf{3 9 0}$ & $\mathbf{4 1 1}$ & $\mathbf{3 1 4}$ & $\mathbf{3 6 3}$ \\
\hline
\end{tabular}


Table 4. Rural vs. urban MU attestation

\begin{tabular}{|l|r|r|r|r|}
\hline $\begin{array}{l}\text { Attested } \\
\text { practice year }\end{array}$ & $\mathbf{2 0 1 1}$ & $\mathbf{2 0 1 2}$ & $\mathbf{2 0 1 3}$ & $\mathbf{2 0 1 4}$ \\
\hline $\begin{array}{l}\text { Employed } \\
\text { Physicians }\end{array}$ & 38 & 74 & 75 & 73 \\
\hline $\begin{array}{l}\text { Independent/ } \\
\text { small practice }\end{array}$ & & & & \\
Physicians & 25 & 133 & 152 & 113 \\
\hline \multicolumn{1}{|c|}{ Total Rural } & $\mathbf{6 3}$ & $\mathbf{2 0 7}$ & $\mathbf{2 2 7}$ & $\mathbf{1 8 6}$ \\
\hline $\begin{array}{l}\text { Employed } \\
\text { Physicians }\end{array}$ & 99 & 117 & 147 & 173 \\
\hline $\begin{array}{l}\text { independent/ } \\
\text { small practice } \\
\text { Physicians }\end{array}$ & 62 & 352 & 427 & 318 \\
\hline \multicolumn{1}{|c|}{ Total Urban } & $\mathbf{1 6 1}$ & $\mathbf{4 6 9}$ & $\mathbf{5 7 4}$ & $\mathbf{4 9 1}$ \\
\hline
\end{tabular}

Table 4 shows that attestation numbers for rural physicians are lower than urban. Attestation by rural physicians is consistently more concentrated around PCP providers: $31 \%$ more PCPs than specialists in this region attested during the four-year period. One factor contributing to this is likely the majority of specialty providers are concentrated in the urban centers. However, without a reliable estimate of the percentage of Hawaii doctors practicing in rural settings [36] we are unable to assess if this difference indicates that having a rural practice impedes MU attestation.

\subsection{Financial implications of MU}

The primary barrier to EHR adoption that the MU program was designed to overcome was financial. Physicians were charged with investing in EHRs, with incentives available to refund initial investment costs. However, incentive payments initially appeared to drive physicians' deeper assimilation of existing EHRs rather than adoption (purchase) of new systems. That is, incentives primarily drove assimilation before adoption (e.g., rapid attestation by employed physicians with existing EHRs) in 2011 and into 2012.

We note this finding in the similarities of physicians initially joining the program (Table 1) and the actual dollar amounts paid to these physicians (Table 5). Table 5 shows that the majority of payments in 2011 went to employed physicians who had existing EMR access in place. In 2012 and 2013, the incentive payments shifted to independent physicians as the number of those providers adopted and attested to MU stage 1 increased. New participation peaked in 2012 with the greatest year-over-year increase in total payments. Table 5 also shows that the level of payments reduced in 2013 from the year prior and again in 2014, as initial assimilation leveled off and meeting MU stage 2 assimilation presented challenges that some physicians were unable to meet.

While the drop off in the amount of MU incentive payments may be attributable to the lower incentive amounts as the program progresses, the count of total attestations and the count of unique attesters also indicate a drop off in year 3 and further drop off in year 4 . Since there appears to be a large percentage of physicians $(65 \%-71 \%)$ who have not yet attested in Hawai' $i$, this indicates adoption and assimilation has stalled, versus the market becoming saturation.

To summarize, this financial distribution is not unexpected given the MU program design, which "front loads" incentive amounts in the first years of the Program. However attestation rates as well dollars paid have dropped significantly in Hawai'i, suggesting the MU program may be reaching its limit in the Hawaii market for motivating either new adoption or further assimilation. It remains to be seen if the next phase of the program - penalizing physicians who do not comply with MU criteria in their reimbursements from the Federal Government - will spur renewed participation.

Table 5. Incentive payments (in millions of US dollars)

\begin{tabular}{|c|c|c|r|r|r|r|}
\hline $\begin{array}{c}\text { Gross Payments } \\
\text { Made Per Calendar } \\
\text { Year }\end{array}$ & 2011 & 2012 & 2013 & \multicolumn{2}{|c|}{2014} & \multicolumn{1}{|c|}{ Grand Total } \\
\hline Stage & 1 & 1 & 1 & 1 & 2 & \\
\hline Employed Physicians & $\$ 2.32$ & $\$ 2.46$ & $\$ 2.10$ & $\$ .90$ & $\$ .68$ & $\$ 8.47 \mathrm{M}$ \\
\hline $\begin{array}{l}\text { Independent/ small } \\
\text { practice Physicians }\end{array}$ & $\$ 1.43$ & $\$ 7.42$ & $\$ 6.52$ & $\$ 3.12$ & $\$ .41$ & $\$ 18.89 \mathrm{M}$ \\
\hline Grand Total & $\$ 3.75 \mathrm{M}$ & $\$ 9.89 \mathrm{M}$ & $\$ 8.62 \mathrm{M}$ & $\$ 4.01 \mathrm{M}$ & $\$ 1.10 \mathrm{M}$ & $\$ 27.35 \mathrm{M}$ \\
\hline
\end{tabular}




\section{Discussion}

The MU program was created with a mission to improve the health and well being of populations through the use of HIT. Specifically, the four main goals include: (i) advancing person-centered and selfmanaged health, (ii) transform health care delivery and community health, (iii) fostering research, scientific knowledge and innovation, and, (iv) enhancing the Nation's HIT infrastructure [3]. Based on the incentive payments in the State of Hawai'i within the first four years of the Medicare MU incentive program, we suggest that the MU program may not be impacting the health care system sufficiently to reach these goals in the timeframe set out by the federal government.

Ubiquitous EHR implementation and use, as the MU program incentivizes, would create the information infrastructure that is needed as a foundation for broader health care reform efforts outlined in the U.S. Affordable Care Act of 2010. If MU goals continue to be met, the availability of individual-level, digital patient records that can be shared electronically and analyzed quickly and automatically will allow for smoother diffusion of other health system innovations such as patientcentered medical homes and accountable care organizations to manage healthcare outcomes at the population level [38]. Continued adoption and assimilation is crucial to success of these initiatives.

Studies have shown that a substantial number of providers continue to lack EHRs. Our analysis of Hawai'i indicating at least two thirds of physicians still did not qualify for MU incentives by 2014. It is unclear if this is due to ineligibility, failure to register, fear of failure at attestation, or other issues [35]. Additionally, failure to adopt and assimilate will likely be the case more consistently in poorer, rural and smaller institutions, where most Americans receive their health care [3]. Moreover, our study of MU attestation among physicians in Hawai' $i$ also illustrates differences in adoption and diffusion among larger groups and small practices, rural practitioner and urban physicians, and primary care and specialist practices.

Turning to our focus on small independent physician practices, this study highlights that the MU payments in Hawaii through 2014 did initially encourage adoption for independent physicians but overwhelmingly did more to incentivize assimilation for large organizations that had already adopted EHRs. These findings are consistent with early predictions by a US Government Accountability Office (GAO) report showing that of "the 2011 hospital recipients of MU funds, $67 \%$ were in urban areas and $46 \%$ were very large (top third by number of beds)" [35]. The empirical data also indicate that adoption and further assimilation has remained low overall with only $35 \%$ of small physician practices attesting at least once during this initial four-year period, and this rate is trending downward. It should be noted that years 2011 and 2012 were optional first years based on stage 1 criteria, which allowed physicians time to purchase EHR tools to meet stage 1 attestation Providers can only attest to receive benefits during a four-year window; that window is sliding with full benefits possible from 2011-2015 or 2012-2016. However, this suggests that attestation rates should continue to climb as physicians have more time to adopt an EMR and learn how to use it. Our empirical analysis suggests there is a drop-off in program participation at least temporarily beginning in 2013 and 2014. The drop-off in attestation rate for independent physicians could indicate the inability for these small practice groups to shift from adoption and initial assimilation to deeper levels of assimilation, and Stage 2 attestation, with few staff resources is not consistently attainable.

If this trend does not change the HITECH goals for enhancing the nation's HIT infrastructure will likely not be fully met. In particular more attention to understanding what the specific needs are for rural and smaller physicians, who serve unique population health needs of these communities [33], is needed. MU policy may evolve to allow for a more flexible orientation for those providers still lacking in EHR to adopt and assimilate the innovation in order to support broader health care reform. An important question with the MU incentive program is whether or not it will continue to provide substantial benefits to large organizations without as effectively reducing barriers for small organizations and independent physicians.

\section{Limitations and future research}

This paper reports on an in depth analysis of the adoption and assimilation of EHRs in physician practices, as evident in and promoted by the Meaningful Use program of the U.S. Federal Government. This study is limited in size and scope to the State of Hawai'i and to a descriptive analysis of secondary data (CMS data).

At the time of this study, Medicaid incentive data was not available for the State of Hawaii. It is possible that observed physician drop-off in MU attestation is due in part to switching from Medicare to Medicaid MU programs. We believe this is true for one large employed physician group. However, MU attestation for employed physicians in large practices has not decreased overall. The small practices in Hawaii that are targeted by the CMS/Medicare versus HI Medicaid programs are different, so that first year attestation in 
the HI Medicaid program in 2014 is not likely to fully explain the drop in CMS/Medicare attestation in 2014. Comparing attestation trends between these two programs would provide insights on how incentive structures affect adoption and assimilation and how physicians respond to different structures. Of note, the Medicaid programs were designed to fund adoption upfront versus the $\mathrm{CMS} / \mathrm{Medicare} \mathrm{MU}$ program requiring both adoption and assimilation at Stage 1 .

Our analysis of MU attestation rates, though finer grained that the CMS statistics, reveals but does not explain why nearly two thirds of Hawaii physicians have yet to respond to this EHR incentive program, what challenges they face, and what challenges or decisions those who have dropped out of the program faced. Interviews and case studies could provide insights on the community resources needed to support these physicians through EHR adoption and assimilation processes, or to assess if further assimilation is even feasible [13]. Comparative cases across states and regions would be particularly useful to understand how the support resources for small practices provided under the HITECH act influenced assimilation rates in other states and communities.

\section{References}

[1] American Institutes for Research (2016). Evaluation of the Regional Extension Center Program. Office of the National Coordinator for Health Information Technology. Final Report.

[2] Ash, J. S., Gorman, P. N., Seshadri, V., \& Hersh, W. R. (2004). Computerized physician order entry in US hospitals: results of a 2002 survey. Journal of the American Medical Informatics Association, 11(2), 95-99.

[3] Blumenthal, D. (2009) Stimulating the Adoption of Health Information Technology. New England Journal of Medicine, 360:15, 1477-1479.

[4] Blumenthal, D. (2010) Launching HITECH. New England Journal of Medicine, 362:5, 382-385.

[5] Blumenthal, D., \& Tavenner, M. (2010). The "meaningful use" regulation for electronic health records. New England Journal of Medicine, 363(6), 501-504.

[6] Centers for Medicare \& Medicaid. (2015) Medicare and Medicaid Incentive Programs. Last Accessed June 8, 2016. http://www.cms.gov/EHRIncentivePrograms/

[7] Centers for Medicare \& Medicaid. (2015) Unique Count of Providers by State. Last Accessed June 8, 2016. https://www.cms.gov/Regulations-andGuidance/Legislation/EHRIncentivePrograms/PU F.html
[8] Centers for Medicare \& Medicaid. (2015) Medicaid Electronic Health Record Incentive Payments for Eligible Professionals. Last Accessed June 8, 2016. https://www.cms.gov/Regulations-andGuidance/Legislation/EHRIncentivePrograms/Da taAndReports.html

[9] Classen, D. C., \& Bates, D. W. (2011). Finding the meaning in meaningful use. New England Journal of Medicine, 365(9), 855-858.

[10] Davidson E. and Chiasson M. (2005) Contextual Influences on Technology Use Mediation: A Comparative Analysis of Electronic Medical Record Systems. European Journal of IS, 14:1, 618.

[11] Davidson, E. and Chismar, W. (2007) The Interaction of Institutionally Triggered and Technology-Triggered Social Structure Change: An Investigation of Computerized Physician Order Entry (CPOE), MIS Quarterly. 31:4, 739758.

[12] Davidson, E. and Heslinga, D. (2007) Bridging the IT Adoption Gap for Small Physician Practices: An Action Research Study on Electronic Health Records. Information Systems Management, 12:1, 15-28.

[13] Davidson, E., Hoffman, E., \& Donahue, M. (2013, January). Will" Meaningful Use" Bridge the Adoption Gap for Small Physician Practices? Results of a Survey of Hawaii Physicians. In System Sciences (HICSS), 2013 46th Hawaii International Conference on (pp. 2595-2604). IEEE.

[14] Department of Health \& Human Services. (2013) Principles and Strategy for Accelerating Health Information Exchange (HIE). Centers for Medicare and Medicaid website. Last accessed June 8, 2016.

[15] Department of Health \& Human Services (2010) Meaningful Use and Critical Access Hospitals. A Primer on HIT Adoption in the Rural Health Care Setting. Centers for Medicare and Medicaid Website. Last accessed June 8, 2016.

[16] Doolan DF and Bates DW (2002) Computerized physician order entry systems in hospitals: mandates and incentives. Health Affairs 21(4), 180-188.

[17] Dykes, P. (2006). The impact of health information technology on the role of nurses \& interdisciplinary communication final results/findings-survey result (3/1/2006). Healthcare Information and Management Systems Society Analytics.

[18] Fichman, R. and Kemerer, C. (1997) The assimilation of software process innovations: an 
organizational learning perspective. Management Science 43:10, 1345-1363.

[19] Fichman, R. and Kemerer, C. (1999) The illusory diffusion of innovation: An examination of assimilation gaps. Information Systems Research, 10:3, 255-275.

[20] Furukawa, M. F., \& Poon, E. (2011). Meaningful use of health information technology: evidence suggests benefits and challenges lie ahead. The American Journal of Managed Care, 17(12 Spec No.), SP76a-SP.

[21] Harle, C. A., Huerta, T. R., Ford, E. W., Diana, M. L., \& Menachemi, N. (2013). Overcoming challenges to achieving meaningful use: insights from hospitals that successfully received Centers for Medicare and Medicaid Services payments in 2011. Journal of the American Medical Informatics Association, 20(2), 233-237.

[22] Heisey-Grove, D., Danehy, L. N., Consolazio, M., Lynch, K., \& Mostashari, F. (2014). A national study of challenges to electronic health record adoption and meaningful use. Medical Care, 52(2), 144-148.

[23] Hussain, A. A. (2011). Meaningful use of information technology: a local perspective. Annals of Internal Medicine, 154(10), 690-692.

[24] Hsiao, C., Hing, E., Socey, T., and Cai, B. (2011) Electronic Health Record Systems and Intent to Apply for Meaningful Use Incentives Among Office-based Physician Practices: United States, 2001-2011. NCHS Data Brief. No. 79. 11/2011.

[25] Jha, A. K., Burke, M. F., DesRoches, C., Joshi, M. S., Kralovec, P. D., Campbell, E. G., \& Buntin, M. B. (2011). Progress toward meaningful use: hospitals' adoption of electronic health records. The American Journal of Managed Care, 17(12 Spec No.), SP117-24.

[26] Krishnaraj, A., Siddiqui, A., \& Goldszal, A. (2014). Meaningful use: participating in the federal incentive program. Journal of the American College of Radiology, 11(12), 1205 1211.

[27] Lynch, K., Kendall, M., Shanks, K., Haque, A., Jones, E., Wanis, M. G., ... \& Mostashari, F. (2014). The Health IT Regional Extension Center Program: evolution and lessons for health care transformation. Health Services Research, 49(1pt2), 421-437.

[28] Nakamura, M. M., Harper, M. B., Castro, A. V., Feliciano, B. Y., \& Jha, A. K. (2015). Impact of the meaningful use incentive program on electronic health record adoption by US children's hospitals. Journal of the American Medical Informatics Association, 22(2), 390-398.
[29] Patel, V., Jamoom, E., Hsiao, C. J., Furukawa, M. F., \& Buntin, M. (2013). Variation in electronic health record adoption and readiness for meaningful use: 2008-2011. Journal of General Internal Medicine, 28(7), 957-964.

[30] Protection, P., \& Act, A. C. (2010). Patient protection and affordable care act. Public Law, $111,48$.

[31] Rao, S., DesRoches, C., Doelan, K., Campbell, E., Miralles, P., and Jha, A. (2011) Electronic health records in small physician practices: availability, use, and perceived benefits. Journal of the American Medical Informatics Association, $18,271-275$

[32] Reardon, J. L., \& Davidson, E. (2007). An organizational learning perspective on the assimilation of electronic medical records among small physician practices. European Journal of Information Systems, 16(6), 681-694.

[33] Slight, S. P., Berner, E. S., Galanter, W., Huff, S., Lambert, B. L., Lannon, C., ... \& Payne, T. H. (2015). Meaningful use of electronic health records: experiences from the field and future opportunities. JMIR medical informatics, 3(3).

[34] State of Hawaii Department of Human Services (2013) Hawaii Medicaid EHR Incentive Program Provider Manual. Provider Manual Version 1.3. November 2013.

[35] Terry, N. P. (2013). Meaningful adoption: what we know or think we know about the financing, effectiveness, quality, and safety of electronic medical records. Journal of Legal Medicine, 34(1), 7-42.

[36] Withy, Kelley. (2015). Annual Report on Findings from the Hawaii Physician Workforce Assessment Project. Report to the 2016 Legislature. December 2015.

[37] Wittie, M., Ngo-Metzger, Q., Lebrun-Harris, L., Shi, L., \& Nair, S. (2014). Enabling quality: electronic health record adoption and meaningful use readiness in federally funded health centers. Journal for Healthcare Quality.

[38] Wolf, L., Harvell, J., \& Jha, A. K. (2012). Hospitals ineligible for federal meaningful-use incentives have dismally low rates of adoption of electronic health records. Health Affairs, 31(3), 505-513.

[39] Wright, A., Henkin, S., Feblowitz, J., McCoy, A. B., Bates, D. W., \& Sittig, D. F. (2013). Early results of the meaningful use program for electronic health records. New England Journal of Medicine, 368(8), 779-780. 